\title{
Long-term survival of patients with hepatocellular carcinoma with pulmonary and adrenal metastasis: A case report
}

\author{
H.Y.ZHANG, Q.J. WU, C.H. XIE and G. ZHANG \\ Hubei Cancer Clinical Study Center, Department of Radiochemotherapy, \\ Zhongnan Hospital, Wuhan University, Wuhan, Hubei 430071, P.R. China
}

Received September 14, 2011; Accepted December 27, 2011

DOI: $10.3892 /$ etm.2012.455

\begin{abstract}
Hepatocellular carcinoma (HCC) is the most common primary malignant tumor of the liver, and has a poor prognosis. In this study, we reported an exceptional clinical case of primary $\mathrm{HCC}$ with metastatic disease in the lungs 1 year following hepatic resection, and in the left adrenal gland 8 years following hepatic resection. Comprehensive treatments, including partial hepatic resection, systemic chemotherapies with various regimens, such as radiotherapy, were administered to this patient. In this case, there was no intrahepatic recurrence of the malignancy and the metastatic disease was sensitive to chemotherapy and radiotherapy. The patient remained alive and in good health for 10 years following the diagnosis of HCC despite early metastatic disease. This indicates that for certain patients with advanced stage HCC, palliative treatments may still be beneficial to their survival. We also discussed the advance in recent research into HCC treatment.
\end{abstract}

\section{Introduction}

Hepatocellular carcinoma (HCC) is one of the most common malignancies and the most common cause of cancer mortality worldwide (1). The main treatments may be curative, such as hepatic resection, liver transplantation, microwave coagulation and radiofrequency ablation, or palliative, including transarterial chemoembolization (TACE), systemic chemotherapy and targeted therapy with sorafenib, among others (2,3). Although much research has been carried out into the treatment of HCC, the prognosis remains extremely poor. In this study, we report a case of long-term survival from primary HCC with early successive lung and adrenal gland metastasis.

Correspondence to: Dr Gong Zhang, Hubei Cancer Clinical Study Center, Hubei Key Laboratory of Tumor Biological Behaviors, Department of Radiochemotherapy, Zhongnan Hospital, Wuhan University, 169 Dong Hu Road, Wuhan, Hubei 430071, P.R. China E-mail: znyyzhanggong@163.com

Key words: hepatocellular carcinoma, pulmonary and adrenal metastasis, resection, chemotherapy, radiotherapy

\section{Case report}

A 35-year old male was admitted to Zhongnan Hospital (China) in July 2001 due to a computed tomographic (CT) scan, which indicated a low density, space-occupying lesion, sized $10.2 \times 9.8 \mathrm{~cm}$ in the right lobe of the liver (Fig. 1), as well as a blood $\alpha$-fetoprotein (AFP) level of $>350 \mathrm{ng} / \mathrm{ml}$. Liver cancer was suspected and no evidence of metastatic disease was detected. A partial right hepatic lobe resection was performed on August 23, 2001, and a tumor, sized approximately $12 \times 10 \times 10 \mathrm{~cm}$, was concurrently removed. The pathological report demonstrated a moderate-to-poorly differentiated HCC (Fig. 4A). The blood AFP levels decreased gradually, reaching $26.47 \mathrm{ng} / \mathrm{ml}$ by September 11, 2001 (Fig. 5).

Without any adjuvant therapy, regular follow-ups were carried out until July 2002, when the blood AFP level increased to $132.63 \mathrm{ng} / \mathrm{ml}$ and a CT scan revealed small nodules in both lungs, with the largest one $(3.5 \times 3.5 \mathrm{~cm})$ in the right pulmonary hilum (Fig. 2A). No other metastatic disease was detected. A chemotherapy regimen of hydroxycamptothecin (HCPT) $10 \mathrm{mg}$ administered intravenously with a glucose tolerance test (i.v. gtt), on days 1-5 + calcium folinate (CF) $200 \mathrm{mg}$ i.v. gtt, on days 1-5 + fluorodeoxyuridine (FUDR) $1900 \mathrm{mg}$ i.v. gtt, on days 1-5 + mitomycin c $10 \mathrm{mg}$ i.v., on day 1 (HCPT+CF+FUDR+MMC) was repeated every 3 weeks for 7 cycles between September 25, 2002 and June 11, 2003, during which time a repeated CT scan revealed a clear diminution of pulmonary nodules following the 4th cycle (Fig. 2B), and blood AFP levels decreased to $34.08 \mathrm{ng} / \mathrm{ml}$ by March 5, 2003 (Fig. 5). The therapeutic effect was partial remission (PR) (Fig. 2C and D). Later follow-ups revealed a stable disease (SD) until the $\mathrm{CT}$ scan found an enlargement of the pulmonary nodules on May 10, 2004. Another regimen of oxaliplatin (L-OHP) $250 \mathrm{mg}$ i.v. gtt, on day 1 + FUDR $750 \mathrm{mg}$ i.v. gtt, on days 1-5 + CF $300 \mathrm{mg}$ i.v. gtt, on days 1-5 (L-OHP+FUDR+CF) was repeated every 3 weeks for 2 cycles between May 13 and June 3, 2004, and the therapeutic effect was SD.

Pulmonary nodules remained stable and there was no evidence of intrahepatic recurrence. Five years later, on June 10, 2009, a CT scan revealed a left adrenal gland mass sized $4.5 \times 4.5 \mathrm{~cm}$ and an increase in blood AFP level to $329.19 \mathrm{ng} / \mathrm{ml}$. A following positron emission tomography (PET)/CT scan revealed a locally hypermetabolic foci in the left adrenal gland, which indicated the presence of metastatic 

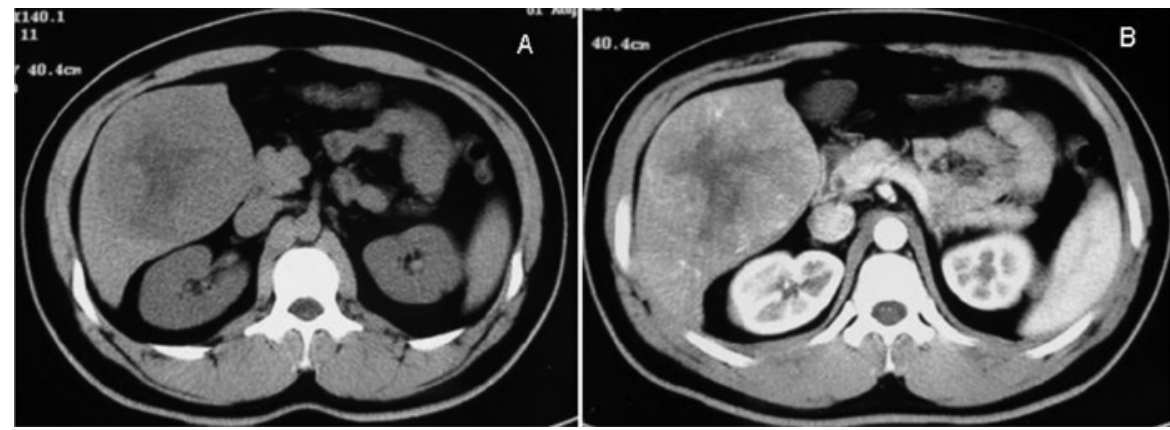

Figure 1. CT prior to hepatic lobe resection. (A) A space-occupying lesion of low density sized $10.2 \times 9.8 \mathrm{~cm}$ in the right hepatic lobe on August $14,2001$. (B) Contrast enhanced (arterial phase) CT revealed the mass had heterogeneous enhancement. CT, computed tomography.
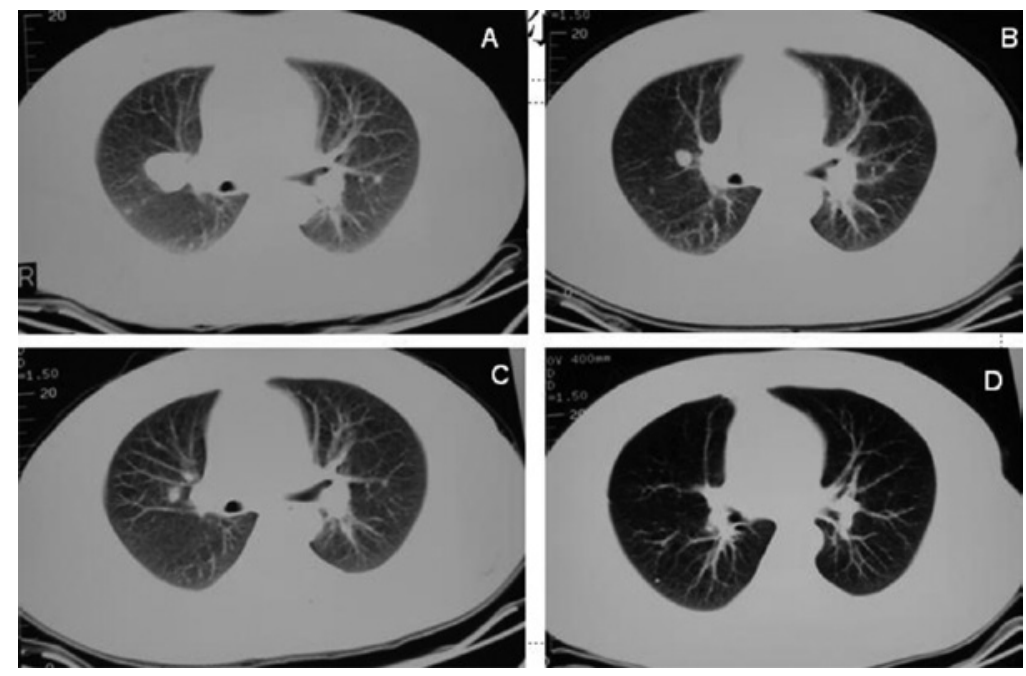

Figure 2. CT of the pulmonary metastatic disease prior to (A) and following (B-D) chemotherapy. (A) A mass sized $3.5 \times 3.5 \mathrm{~cm}$ in the right pulmonary hilum and numerous small nodules in both lungs on September 23, 2002. (B) Following 4 cycles of chemotherapy the nodule in the right pulmonary hilum sized $1.5 x 1.5 \mathrm{~cm}$ and small nodules in both lungs had decreased by December 19, 2002. (C) Following 6 cycles of chemotherapy, the nodules in both lungs had reduced in size by March 4, 2003. (D) Following 7 cycles of chemotherapy there were only a few, very small nodules in both lungs by March 31, 2004. CT, computed tomography.
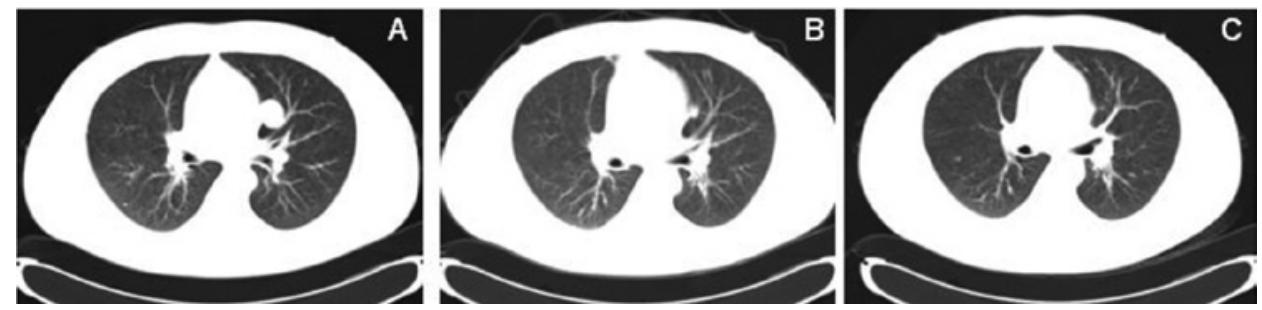

Figure 3. CT of the pulmonary metastatic disease prior to (A) and following (B and C) radiochemotherapy. (A) Pulmonary mass near the left cardiac border sized 2.5x2.5 cm on September 16 2009. (B) The nodule near the left cardiac border, sized $0.5 \times 0.5 \mathrm{~cm}$, on December 9, 2009. (C) The nodule near the left cardiac border had disappeared by January 3, 2010. CT, computed tomography.

disease. A laparoscopic left adrenalectomy was performed on July 14, 2009 and the pathological report revealed a metastatic hepatoma (Fig. 4B). Following this, blood AFP levels decreased sharply (Fig. 5). The patient received 2 cycles of capecitabine $1.5 \mathrm{~g}$, per os (p.o.), twice daily (bid), on days 1-14 + L-OHP 200 mg, i.v. gtt, on day 1 (XELOX); repeated every 3 weeks in August and September 2009.

On September 16, 2009, a CT scan found an enlarged pulmonary nodule of $2.5 \times 2.5 \mathrm{~cm}$ near the left cardiac border, with no change in the remaining lesions (Fig. 3A), and blood AFP levels were $193.44 \mathrm{ng} / \mathrm{ml}$. A 3-dimensional conformal radiation therapy (3DCRT) was administered (total dose, $57.5 \mathrm{~Gy} / 2.5 \mathrm{~Gy} / 23 \mathrm{~F}$ ) to the pulmonary nodule near the left cardiac border between September 24, and November 23, 2009, during which time the patient received 2 cycles of irinotecan $280 \mathrm{mg}$ i.v. gtt, on day 1; CF $300 \mathrm{mg}$ i.v. gtt, on days 1-2; fluorouracil $750 \mathrm{mg}$ i.v. gtt, on days 1-2; fluorouracil $1000 \mathrm{mg}$ by continuous intravenous infusion (CIV), on days 1-2 (FOLFIRI); repeated every 2 weeks. A CT scan on December 9, 2009 revealed that the pulmonary nodule near the left cardiac border was clearly diminished (Fig. 3B and C). The later follow-ups revealed SD until the CT scan found an enlargement of the 


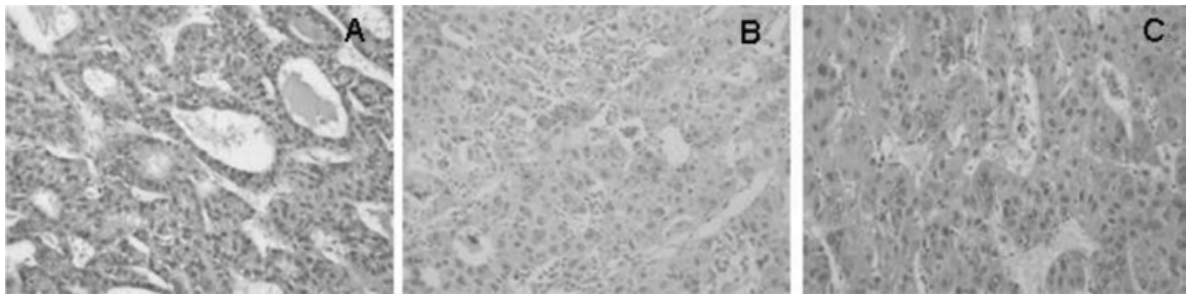

Figure 4. The pathological report of the three surgeries (x100). (A) Moderate-to-poorly differentiated hepatocellular carcinoma (liver). (B) Metastatic hepatoma (left adrenal gland). (C) Metastatic hepatocellular carcinoma (left lung).

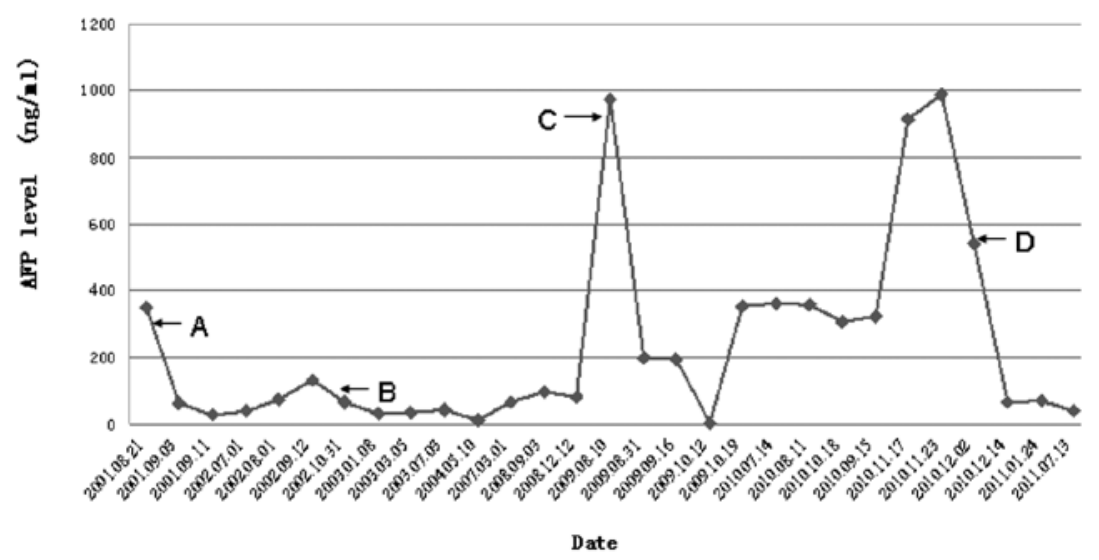

Figure 5. The change of blood AFP levels throughout the course of disease. (A) A partial right hepatic lobe resection was performed on August 23, 2001. (B) A chemotherapy regimen (HCPT+CF+FUDR+MMC) was administered for 7 cycles between September 25, 2002 and June 11, 2003. (C) A laparoscopic left adrenalectomy was performed on July 14, 2009. (D) A video-assisted thoracoscopic left upper pulmonary wedge resection was performed on December 2, 2010. AFP, $\alpha$-fetoprotein; HCPT+CF+FUDR+MMC, hydroxycamptothecin + calcium folinate + fluorodeoxyuridine + mitomycin c

left lung nodule below the chest wall. On November 26, 2010, it was found that the left upper lung nodule had grown up to $29 \mathrm{~mm}$ in diameter; no other clear metastasis was noted. The blood AFP levels increased to $540.55 \mathrm{ng} / \mathrm{ml}$. A video-assisted, thoracoscopic left upper pulmonary wedge resection was performed on December 2, 2010 and the pathological report demonstrated a metastatic HCC (Fig. 4C). The blood AFP levels following surgery decreased gradually from $181.9 \mathrm{ng} / \mathrm{ml}$ on December 6, 2010 to $37.5 \mathrm{ng} / \mathrm{ml}$ on July 13, 2011 (Fig. 5).

Throughout the course of the disease, the blood AFP was very sensitive to the treatment, especially to the operations (Fig. 5). Since the disease was founded, the patient had a good performance status and Child-Pugh A disease. With regard to personal history, a liver disease of Schistosomiasis japonic was diagnosed and cured in 1997, hepatitis B was diagnosed in 2001, and the patient had a long history of smoking (10 cigarettes per day for 20 years). There was no other special personal or family history.

\section{Discussion}

Primary liver cancer, HCC being the major subtype, is one of the most common malignancies and the most common cause of cancer mortality worldwide (1). An estimated 748,300 new cases and 695,900 cancer fatalities occurred worldwide in 2008, half of which were in China (4). Viral infection is the most common cause of $\mathrm{HCC}$, in which hepatitis B virus (HBV) and hepatitis $\mathrm{C}$ virus (HCV) infections account for approximately 60 and $33 \%$ of the total liver cancer cases in developing countries, respectively; whereas these account for 23 and $20 \%$ of cases in developed countries $(5,6)$. Metastases are common in patients with HCC. The frequent sites of extrahepatic metastasis include the lung, abdominal lymph node, adrenal gland and bone $(7,8)$. Although much research has been carried out into the treatment of HCC, the prognosis remains extremely poor. For patients at early stages of the disease, well-selected, 5-year survival rates may increase to $60-70 \%$, and for those at advanced stages, there is as yet no benefit of survival from systemic therapies (9).

With great improvement of survival results following hepatic surgery, hepatic resection remains the main therapy for those early-stage HCC patients who are not suitable for liver transplantation (10). Ikai et al reported the 15th follow-up survey of primary liver cancer in $6,785 \mathrm{HCC}$ patients with cirrhosis who underwent hepatic resection between 1988 and 1999, the 1-, 3-, 5- and 10-year survival rates were 85, 64, 45 and $21 \%$, respectively (11). Liver transplantation is the optimal treatment approach for those strictly selected patients with unresectable disease. It is based on the Milan criteria, which supports transplantation in the setting of 1 lesion of $\leq 5 \mathrm{~cm}$ or up to 3 lesions of $\leq 3 \mathrm{~cm}$ in diameter (12).

Compared to other neoplasms, HCC is resistant to most conventional chemotherapeutic agents. Monotherapy, mainly with anthracyclines, including doxorubicin and 4'-epidoxorubicin, may obtain a response rate of $10-15 \%$ (13). Combined chemotherapy has also been explored. Urabe et al reported an objective response rate [complete response (CR)+PR] of $46.7 \%$ in 16 patients administered combination therapy with methotrexate, 5-fluorouracil, cisplatin and interferon- $\alpha-2 b$ (14). A 
phase II study of combined chemotherapy containing new agents, such as gemcitabine, L-OHP and bevacizumab in 33 patients with $\mathrm{HCC}$ reported an objective response rate of $20 \%$ (15). However, these results should be confirmed by further large-scale, multi-center, randomized, controlled trials.

In recent years, targeted therapies have been intensively researched. There are studies showing that the multi-kinase inhibitor, sorafenib, may potentially be effective in the treatment of HCC. In the multicenter, phase III, double-blind, placebocontrolled Sorafenib HCC Assessment Randomized Protocol (SHARP) Trial in patients with advanced HCC, who had not received previous systemic treatment, Josep et al reported that the median survival and the time to radiological progression were almost 3 months longer for patients treated with sorafenib $(n=299)$ than for those administered the placebo $(n=303$; 10.7 months in the sorafenib group vs. 7.9 months in the placebo group; hazard ratio in the sorafenib group, $0.69 ; 95 \%$ confidence interval, 0.55-0.87; $\mathrm{P}<0.001)$. However, the median time to symptomatic progression between the two groups revealed no significant difference. Other agents, including mapatumumab, bevacizumab and erlotinib, among others, which show potential effects are also in their early research phase (16-18).

Despite the fact that patients with $\mathrm{HCC}$ generally experience very poor outcomes, there are unique examples that present us with long-term survivors of HCC following combined treatment. Shirabe et al report a case of 8 years and 9 months with a resectable solitary peritoneal recurrence at the site of the incision following initial hepatic resection for ruptured HCC (19). Schreibman et al reported another case of 9 years and 9 months with recurrent HCC 6.5 years following liver transplantation (20). In a study of the clinicopathological features of patients surviving for more than 20 years following resection for HCC, Zhou et al reported that 53 cases survived for more than 20 years, in which the longest case survived for 43 years and 2 months and another survived for 37 years, free of disease (21).

In this study, we report a case of primary HCC with metastatic disease in the lungs and left adrenal gland, and comprehensive treatments, including partial hepatic resection, systemic chemotherapy, radiotherapy for the metastatic mass in the left lung, left adrenalectomy and left upper pulmonary wedge resection. Although worldide HCC has a poor outcome, in this case, the patient remained alive and well for 10 years following diagnosis of the malignancy. Of note, is that despite the early presentation of metastatic diseases elsewhere, there was no clear evidence of intrahepatic recurrence of the malignancy throughout the course of disease, and the patient had Child-Pugh stage A disease at all times. Of note, the metastatic disease in the lung was sensitive to chemotherapy and radiotherapy. This indicates that for certain patients with advanced stage HCC, palliative treatments may still be benefcial to their survival. Perhaps by deminishing the burden of the tumor and lowering the clinical stage, the progression of the disease may be retarded and thus the patient's quality of life may be improved. Although certain chemotherapeutic regimens turned out to be effective, there is little evidence, and this is one of the limitations of our treatments. This area is therefore worthy of further research. Nevertheless, there remains a risk of future disease recurrence, and targeted therapy may thus, be an option. Since HCC remains a major health problem worldwide, it is crucial that we keep on searching for new approaches for the recognition and the treatment of HCC.

\section{References}

1. Jemal A, Bray F, Center MM, Ferlay J, Ward E and Forman D: Global cancer statistics. CA Cancer J Clin 61: 69-90, 2011.

2. Okuda K: Hepatocellular carcinoma. J Hepatol, 32: 225-237, 2000.

3. Llovet JM, Burroughs A and Bruix J: Hepatocellular carcinoma. Lancet 362: 1907-1917, 2003.

4. Ferlay J, Shin HR, Bray F, Forman D, Mathers C and Parkin DM: Estimates of worldwide burden of cancer in 2008: GLOBOCAN 2008. Int J Cancer 127: 2893-2917, 2010.

5. Raza SA, Clifford GM and Franceschi S: Worldwide variation in the relative importance of hepatitis $\mathrm{B}$ and hepatitis $\mathrm{C}$ viruses in hepatocellular carcinoma: a systematic review. Br J Cancer 96: 1127-1134, 2007.

6. Parkin DM: The global health burden of infection-associated cancers in the year 2002. Int J Cancer, 118: 3030-3044, 2006

7. Katyal S, Oliver JR, Peterson MS, Ferris JV, Carr BS and Baron RL: Extrahepatic metastases of hepatocellular carcinoma. Radiology 216: 698-703, 2000.

8. Kummar S and Shafi NQ: Metastatic hepatocellular carcinoma. Clin Oncol (R Coll Radiol) 15: 288-294, 2003.

9. Lopez PM, Villanueva A and Llovet JM: Systematic review: evidence-based management of hepatocellular carcinoma - an updated analysis of randomized controlled trials. Aliment Pharmacol Ther 23: 1535-1547, 2006.

10. Belghiti J, Cortes A, Abdalla EK, Régimbeau JM, Prakash K, Durand F, Sommacale D, Dondero F, Lesurtel M, Sauvanet A, Farges O and Kianmanesh R: Resection prior to liver transplantation for hepatocellular carcinoma. Ann Surg 238: 885-893, 2003.

11. Ikai I, Itai Y, Okita K, Omata M, Kojiro M, Kobayashi K, Nakanuma Y, Futagawa S, Makuuchi M and Yamaoka Y: Report of the 15th follow-up survey of primary liver cancer. Hepatol Res 28: 21-29, 2004.

12. Mazzaferro V, Regalia E, Doci R, Andreola S, Pulvirenti A, Bozzetti F, Montalto F, Ammatuna M, Morabito A and Gennari L: Liver transplantation for the treatment of small hepatocellular carcinomas in patients with cirrhosis. N Engl J Med 334: 693-699, 1996.

13. Lai EC and Lau WY: The continuing challenge of hepatic cancer in Asia. Surgeon 3: 210-215, 2005.

14. Urabe T, Kaneko S, Matsushita E, Unoura M and Kobayashi K: Clinical pilot study of intrahepatic arterial chemotherapy with methotrexate, 5 -fluorouracil, cisplatin and subcutaneous interferon-alpha- $2 \mathrm{~b}$ for patients with locally advanced hepatocellular carcinoma. Oncology 55: 39-47, 1998.

15. Zhu AX, Blaszkowsky LS, Ryan DP, Clark JW, Muzikansky A, Horgan K, Sheehan S, Hale KE, Enzinger PC, Bhargava P and Stuart K: Phase II study of gemcitabine and oxaliplatin in combination with bevacizumab in patients with advanced hepatocellular carcinoma. J Clin Oncol 24: 1898-1903, 2006.

16. Hotte SJ, Hirte HW, Chen EX, Siu LL, Le LH, Corey A, Iacobucci A, MacLean M, Lo L, Fox NL and Oza AM: A phase 1 study of mapatumumab (fully human monoclonal antibody to TRAIL-R1) in patients with advanced solid malignancies. Clin Cancer Res 14: 3450-3455, 2008.

17. Siegel AB, Cohen EI, Ocean A, Lehrer D, Goldenberg A, Knox JJ, Chen H, Clark-Garvey S, Weinberg A, Mandeli J, et al: Phase II trial evaluating the clinical and biologic effects of bevacizumab in unresectable hepatocellular carcinoma. J Clin Oncol 26: 2992-2998, 2008.

18. Thomas MB, Chadha R, Glover K, Wang X, Morris J, Brown T, Rashid A, Dancey J and Abbruzzese JL: Phase 2 study of erlotinib in patients with unresectable hepatocellular carcinoma. Cancer 110: 1059-1067, 2007.

19. Shirabe K, Kitamura M, Tsutsui S, Maeda T, Matsumata $T$ and Sugimachi K: A long-term survivor of ruptured hepatocellular carcinoma after hepatic resection. J Gastroenterol Hepatol 10: 351-354, 1995.

20. Schreibman IR, Bejarano P, Martinez EJ and Regev A: Very late recurrence of hepatocellular carcinoma after liver transplantation: case report and literature review. Transplant Proc 38: 3140-3143, 2006.

21. Zhou XD, Tang ZY, Ma ZC, Fan J, Wu ZQ, Qin LX, Zhou J, Yu Y, Sun HC and Qiu SJ: Twenty-year survivors after resection for hepatocellular carcinoma-analysis of 53 cases. J Cancer Res Clin Oncol 135: 1067-1072, 2009. 